\title{
GLASS TRANSITION AND INTERFACIAL SEGMENTAL DYNAMICS IN POLYMER-PARTICLE COMPOSITES
}

\author{
C. G. ROBERTSON ${ }^{\#}$ \\ Saint-Gobain High-Performance Materials, Northboro Research and Development Center \\ NORTHBORO, MA 01532-1545 \\ C. M. ROLAND* \\ Chemistry Division, Code 6120, Naval Research Laboratory, Washington, DC 20375-5342
}

\section{CONTENTS}

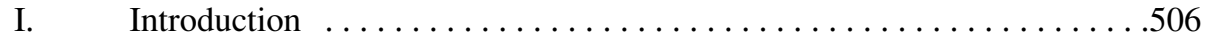

II. Dynamic Mechanical Spectroscopy . . . . . . . . . . . . . . . . . . .507

III. Nuclear Magnetic Resonance . . . . . . . . . . . . . . . . . . . . . . . 510

IV. Dielectric Spectroscopy . . . . . . . . . . . . . . . . . . . . . .514

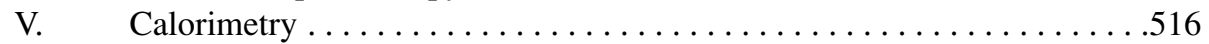

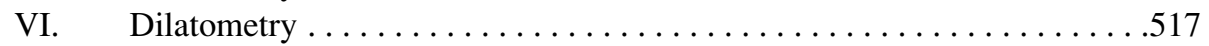

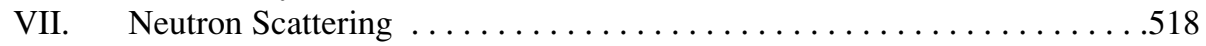

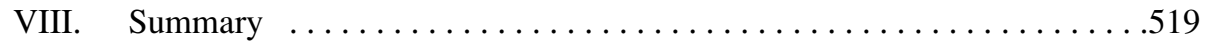

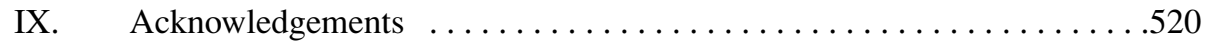

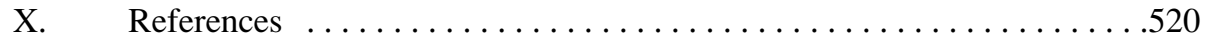

\begin{abstract}
We review the literature concerned with the effect of proximity to a filler surface on the local segmental mobility of polymer chains. This mobility is commonly assessed from either the glass transition temperature, $T_{g}$, or the segmental relaxation times measured by mechanical, dielectric, or NMR spectroscopy. Published studies report increases, decreases, or no change in $T_{g}$ upon the addition of carbon black, silica, and other reinforcing fillers. Similarly, the segmental relaxation times have been found to increase or be invariant to the presence of nanometer-sized particles. Some of these discrepancies can be ascribed to ambiguous methods of data analysis; others likely reflect the variation in fillerpolymer interaction among different systems. There are unequivocal examples of polymers that have segmental dynamics and glass transitions unaffected by nano-particle reinforcement. However, the general principles governing the behavior remain to be clarified, with further work, focusing on the micromechanics at the particle interface, required for resolution of this important aspect of rubber science and technology.
\end{abstract}

\section{INTRODUCTION}

Utilization of rubber often relies on the incorporation of small-particle fillers, which improve processability and physical properties, especially the mechanical performance. Since fillers often also reduce material costs, it is unsurprising that rubber reinforced with carbon black, silica, etc., is the most widely used polymeric composite. The most common filler is carbon black, employed as a pigment on Egyptian pottery as early as $4000 \mathrm{BC}$ and as a reinforcing agent for rubber since the early $20^{\text {th }}$ century. Methods to incorporate nanometer-sized fillers, the distribution and dispersion of the particles, and their effect on properties are aspects of the technology that have been widely reviewed..$^{1-7}$ Interest has been rekindled recently as part of the burgeoning attention to nanoscience and technology broadly defined. ${ }^{8,9}$ However, we eschew herein a general consideration of polymer nanoconfinement; that situation is somewhat confused, as described in a recent review. ${ }^{10}$ Our focus is the dynamics of polymer chains at the interface with carbon black, silica, and similar particulate, reinforcing fillers.

* Ph: 202-767-1719; Fax: 202-767-0594; email: roland@nrl.navy.mil

\# Ph: 508-351-7180; Fax: 508-351-7805; email: christopher.g.robertson@saint-gobain.com 


\section{DYNAMIC MECHANICAL SPECTROSCOPY}

Dynamic mechanical testing is a common technique to study the effect of particles on the $T_{g}$ of polymers, ${ }^{11-23}$ and a summary of these studies is given in Table I. Many investigators draw conclusions based on the temperature of the maximum in the isochronal loss tangent, $\tan \delta=$ $G^{\prime \prime} / G^{\prime}$ (abbreviations are defined in the appendix). This can be problematic because $\tan \delta$ in the glass-to-rubber softening region is influenced not only by the local segmental dynamics, as reflected in the magnitude of the loss modulus toward lower $T$, but also by filler-induced changes in both $G$ ' and $G$ " at higher $T$. As shown recently by Robertson $e t$ al. for BR reinforced with carbon black or SBR reinforced with silica, ${ }^{23}$ the shape and position of the loss modulus peak are unaffected by particle surface area and the intensity of the polymer-filler interaction, despite substantial changes in the loss tangent peaks (see Figure 1). Vieweg et al. ${ }^{21}$ also reported negligible modification of the segmental relaxation behavior in filled SBR, as illustrated in Figure 2. (For comparing isochronal and isothermal data, a decade in time or frequency corresponds to roughly a temperature change of $2-3{ }^{\circ} \mathrm{C}$ for polymers near $\left.T_{g}\right)$. There are examples of shifts in both the loss modulus and tan $\delta$ peaks when small particulates are added to polymers (e.g., Reid and Greenberg. ${ }^{18}$ ) However, interpretations of the effect of filler on $T_{g}$ based solely on changes in $\tan \delta$ are open to question.

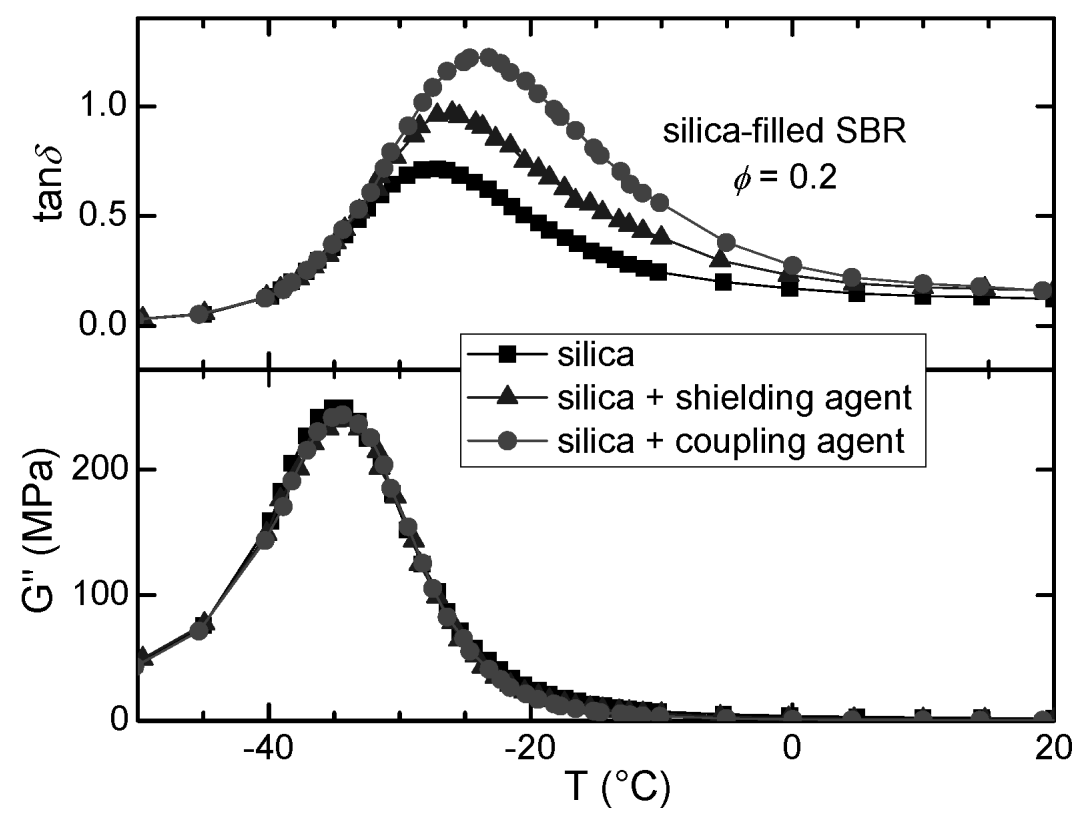

FIG. 1. - Mechanical loss tangent (top) and loss modulus (bottom) measured at a strain amplitude of $0.25 \%$ for SBR with $20 \%$ silica by volume. (Adapted from Ref. 23) 
TABLE I

Dynamic Mechanical Spectroscopy Results

\begin{tabular}{|c|c|c|}
\hline$\overline{\text { System }}$ & Conclusion & Reference \\
\hline Silica in SBR & $\begin{array}{l}\text { New peak } \sim 105 \text { deg above } \\
\text { normal } T_{g} ; \text { Layer thickness } \\
=\text { few nm }\end{array}$ & Ref. [22] \\
\hline Silica in SBR & $\begin{array}{l}\text { Used } 3 \text { phase model to ascribe } \\
\text { Payne effect to bound rubber }\end{array}$ & Ref. [20] \\
\hline $\begin{array}{l}\text { Poly(acrylic acid) filled } \\
\text { w/ silica, aluminum oxide, } \\
\text { or calcium silicate }\end{array}$ & $\begin{array}{l}\text { Increase of } \tan \delta \text { peak of } \leq 15{ }^{\circ} \mathrm{C} \\
\text { for calcium silicate; no effect } \\
\text { for other fillers }\end{array}$ & Ref. [17] \\
\hline $\begin{array}{l}\text { Various acrylic polymers } \\
\text { filled with silica }\end{array}$ & $\begin{array}{l}\text { Increase of tand peak of } \\
\leq 20^{\circ} \mathrm{C} \text {; smaller shift for G" } \\
\text { peak and virtually no shift in } \\
\text { DSC } T_{g}\end{array}$ & Ref. [18] \\
\hline $\begin{array}{l}\text { Poly (styrene- } \mathrm{CO}^{-} \\
\text {acrylonitrile) } \\
\text { with carbon fibers or } \\
\text { carbon particles }\end{array}$ & $\begin{array}{l}\text { Loss modulus peak broadened } \\
\text { towards higher } \mathrm{T}\end{array}$ & Ref. [15] \\
\hline Carbon black/SBR & Tand peak increase of $\sim 30^{\circ} \mathrm{C}$ & Ref. [13] \\
\hline $\begin{array}{l}40 \mathrm{~nm} \text { PS particles } \\
\text { in } \mathrm{SBR}\end{array}$ & $\begin{array}{l}\text { Loss peak shifted } \sim 4^{\circ} \mathrm{C} ; \tan \delta \\
\text { peak position unchanged; } \\
\text { dilatometric } T_{g} \text { unchanged; } \\
\text { no immobilized filler }\end{array}$ & Ref. [14] \\
\hline $\begin{array}{l}\text { Silica in PVAc, PS, } \\
\text { PMMA, and } \\
\text { poly(4-vinylpyridine) }\end{array}$ & $\begin{array}{l}\text { Tan } \delta \text { peak at same freq, } \\
\text { lower height, with new } \\
\text { peak at higher } T\end{array}$ & Refs. [11,12] \\
\hline $\begin{array}{l}\text { Carbon black and } \\
\text { highly crosslinked BR } \\
\text { particles in SBR }\end{array}$ & $\begin{array}{l}\text { No change in peak frequency } \\
\text { of loss modulus }\end{array}$ & Ref. [21] \\
\hline $\begin{array}{l}\text { Silica } \mathrm{w} / \\
\text { polyethylacrylate } \mathrm{w} / \\
\text { grafted silane }\end{array}$ & $\begin{array}{l}\text { Gradient of } T_{g} \text { around particle } \\
\text { inferred from T-dependence } \\
\text { of viscoelastic data }\end{array}$ & Ref. [18] \\
\hline $\begin{array}{l}\text { Carbon black in BR } \\
\text { and silica in SBR }\end{array}$ & $\begin{array}{l}\text { No effect in G" peak location } \\
\text { or shape; changes in tan } \delta \text { peak }\end{array}$ & Ref. [23] \\
\hline
\end{tabular}




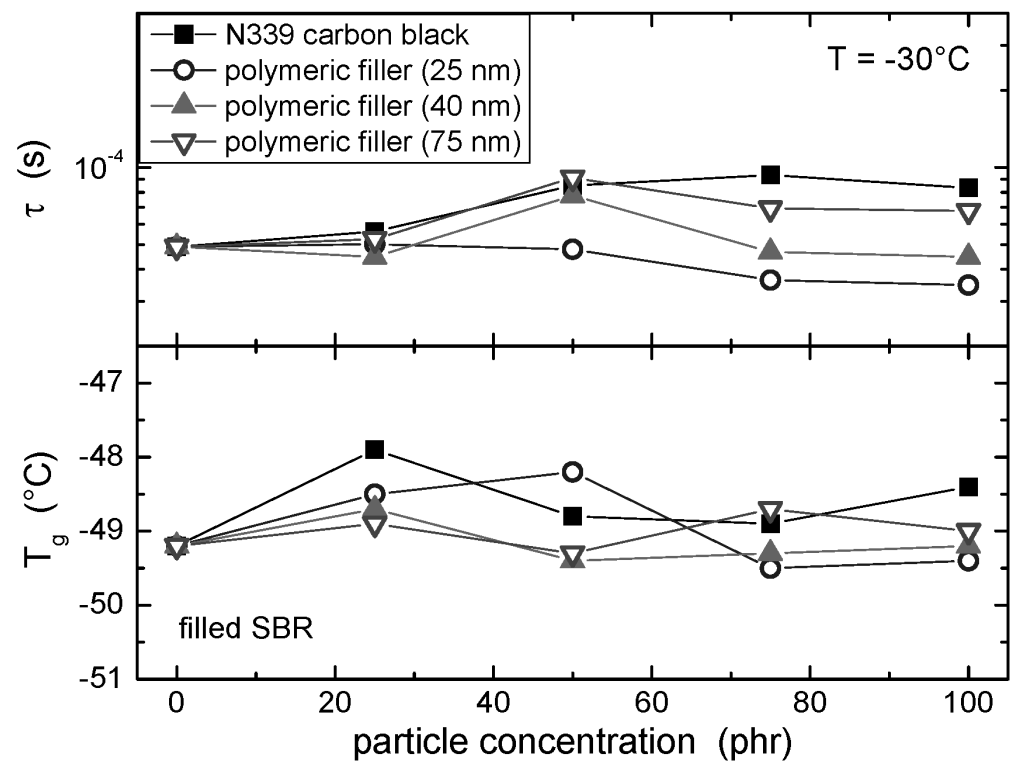

FIG. 2. - Segmental relaxation time (top) and glass transition temperature (bottom) of SBR reinforced with either carbon black or highly crosslinked BR particles of various size. (Adapted from Ref. 21)

Highly cited work concerning the influence of filler on the viscoelastic glass transition is that of Tsagaropoulos and Eisenberg. ${ }^{11,12}$ They found a second $\tan \delta$ peak in isochronal measurements on various uncrosslinked polymers filled with $\mathrm{nm}$ silica particles. This peak, occurring at temperatures as much as $100^{\circ} \mathrm{C}$ above the primary (softening transition) tan $\delta$ peak, was ascribed to the glass transition of immobilized chains near the particles. As reproduced in Figure 3, however, this putative "second glass transition" is in the viscoelastic zone associated with terminal flow of the polymer, suggesting an alternate interpretation: The terminal relaxation process (chain diffusion) of uncrosslinked polymer can be suppressed by interaction with particles. This means that only chains unaffected by the particles flow within the usual range of temperature or frequency. The gives rise to a terminal dispersion (loss tangent peak), rather than the usual divergence of $\tan \delta$ toward infinity with increasing temperature (or decreasing frequency). A similar phenomenon is observed in sparsely branched polymers and bidisperse polymer blends, ${ }^{24-26}$ crosslinked polymer networks containing unattached chains, ${ }^{27-29}$ and particle-reinforced polymers. ${ }^{30-32}$ This ambiguity in the results of Tsagaropoulos and Eisenberg ${ }^{11,12}$ illustrates the caution required when interpreting viscoelastic data in terms of the effect of filler on the glass transition behavior. 


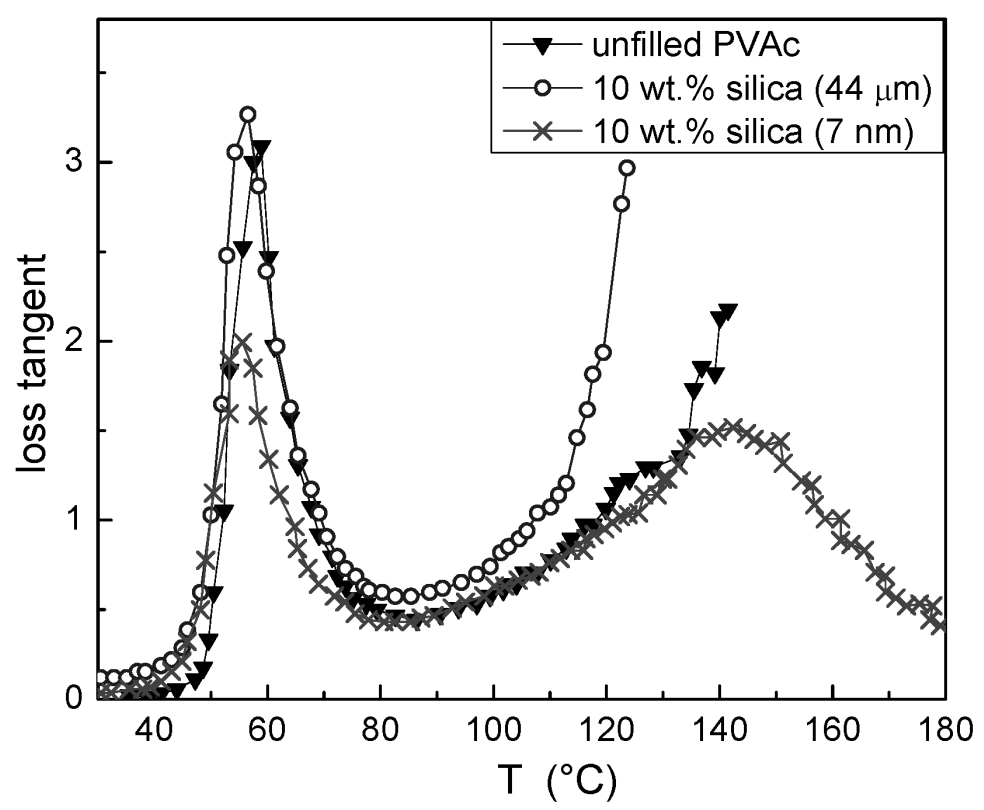

FIG. 3. - Mechanical loss tangent for PVAc neat and with silica particles of the indicated size. The peaks at low $T$ are the usual softening dispersion, while the upturn at higher $T$ is due to flow (Adapted from Ref. 11)

\section{NUCLEAR MAGNETIC RESONANCE}

The most common NMR approach for characterizing polymer motions in the presence of filler is to measure proton spin-spin relaxation times $\left(\mathrm{T}_{2}\right)$ by analyzing spin echoes formed using various pulse sequences (Table II). An immediate complication is that chains attached to filler particles, as well as any chemically-crosslinked chains, undergo restricted, anisotropic motion. This suppresses motional narrowing of the spectral lines, complicating efforts to quantify the relaxation processes. ${ }^{33,34}$ It is not always clear from experimental studies that a distinction is made between chain segments immobilized by their spatial proximity to filler particles versus specific backbone units adsorbed at specific sites on the filler surface. The difference was brought out in the work of Dutta et al. ${ }^{35}$ who found that only the olefinic carbons in SBR were immobilized, indicating that specific interaction at the surface caused the observed immobilization. This is quite different from an interpretation of a "glassy" shell in the interfacial region. 
TABLE II

NMR RESULTS

\begin{tabular}{|c|c|c|}
\hline System & Conclusion & Reference \\
\hline$\overline{\text { Carbon black in NR }}$ & No immobilization & Ref. [44] \\
\hline Carbon black in SBR & $\begin{array}{l}\text { Immobilized, intermediate } \\
\text { mobility, and mobile phases }\end{array}$ & Ref. [41] \\
\hline $\begin{array}{l}\text { Silica in end- } \\
\text { methylated PDMS }\end{array}$ & Fixed and mobile chain units & Ref. [51] \\
\hline$\overline{\text { Carbon black in BR }}$ & $\begin{array}{l}\text { Chain units directly attached } \\
\text { to filler are immobilized }\end{array}$ & Ref. [38] \\
\hline$\overline{\text { Carbon black in NR }}$ & $\begin{array}{l}\text { Immobilization of chains } \\
\text { attached to active filler sites }\end{array}$ & Ref. [42] \\
\hline$\overline{\text { Carbon in NR }}$ & $\begin{array}{l}\text { Immobilized layer that is } \\
\text { unaffected by solvent }\end{array}$ & Ref. [40] \\
\hline Carbon black in NR & Reduced segmental mobility & Ref. [56] \\
\hline $\begin{array}{l}\text { Carbon black in } \\
\text { BR and EPDM }\end{array}$ & Immobilized chains & Ref. [39] \\
\hline Carbon black in SBR & No immobilization & Ref. [53] \\
\hline Carbon black in BR & Two phases of different mobility & Ref. [57] \\
\hline$\overline{\text { Carbon black in NR }}$ & $\begin{array}{l}\text { After extraction in boiling } \\
\text { solvents } 3-8 \mathrm{~nm} \text { thick } \\
\text { bound layer detected }\end{array}$ & Ref. [37] \\
\hline Carbon black in IR & No immobilization & Ref. [34] \\
\hline Carbon black in IR & Reduced segmental mobility & Ref. [33] \\
\hline$\overline{\text { Carbon black in BR }}$ & $\begin{array}{l}\text { No change in } T_{g} \text { but restricted } \\
\text { mobility of interfacial layer }\end{array}$ & Ref. [55] \\
\hline $\begin{array}{l}\text { Carbon black in EPDM } \\
\text { EPDM }\end{array}$ & $\begin{array}{l}\text { Increased mobility and small } \\
\text { change of } T_{g} \text { due to filler }\end{array}$ & Ref. [36] \\
\hline Carbon black in SBR & $\begin{array}{l}\text { Only olefinic protons } \\
\text { specifically bound to filler } \\
\text { show constrained motion }\end{array}$ & Ref. [35] \\
\hline $\begin{array}{l}\text { Carbon black in } \\
\text { EPDM, IR, and butyl- } \\
\text { methylstyrene copolymer }\end{array}$ & $\begin{array}{l}\text { No immobilization of EPDM; } \\
\text { reduced mobility for IR and } \\
\text { copolymer. }\end{array}$ & Ref. [52] \\
\hline $\begin{array}{l}\text { Silica with grafted } \\
\text { silane copolymerized } \\
\text { with polyethylacrylate }\end{array}$ & Immobilized phase at lower T & Ref. [45] \\
\hline
\end{tabular}

Accurate identification of species according to their mobility requires use of different pulse sequences; ${ }^{36,37}$ however, this caveat is usually ignored. The usual approach is to fit proton relaxation curves (e.g., free induction decay and/or spin echo relaxation) to a sum of functions, with the number of terms equated to the number of polymer domains (or phases). Typically one or two domains are reported, each defined by their mobility, in reflection of the use of one or two terms to fit the decay data. The least mobile phase is assumed to be polymer segments either attached at specific sites on the filler particle or residing in the interfacial region. Polymer chains unaffected by the filler comprise the mobile phase. Sometimes a third phase is reported, with inter- 
mediate mobility presumably due to intermediate proximity to the filler. There are obvious problems with analyses of this type. The relaxation curves are generally featureless, and there is no guarantee that any fitting procedure is unique. The use of different fitting functions can lead to a different number of terms, ostensibly implying different numbers of polymer domains. Sometimes the rubber is extracted, so that only the bound polymer and filler are measured in the NMR spectrometer; eliminating the soluble ("free") chains enhances the response of the bound rubber. An additional complication in analyzing the relaxation is removal of any background signal, which must be done correctly since it can have a substantial effect on the shape of the relaxation curve. ${ }^{38}$

Functional forms that have been assumed to fit NMR relaxation curves measured for filled rubber include: (i) simple exponential decay, ${ }^{35,39,40}$ which assumes different domains exert no reciprocal influence (i.e., an absence of mutual interference of different NMR frequencies). This is expected only for homogeneous relaxation of isolated species, which is not an accurate description for a neat, entangled polymer or any material near its glass transition. (ii) Gaussian decay, ${ }^{41}$ which is a common shape for dipolar-broadened lines in solids, but not the correct function when molecular motions are significant; (iii) Weibull distribution, ${ }^{37,42}$ a very general empirical line shape; (iv) normal and log-normal distributions functions, ${ }^{36}$ and (v) more complicated equations such as the relaxation function proposed by Cohen-Addad ${ }^{43}$ or having different decay functions (not just different time constants) for the mobile and (presumed) immobilized fraction. ${ }^{44-46}$

We demonstrate the problem with this approach by fitting FID curves reported by Kaufman et al. ${ }^{39}$ for BR with $50 \mathrm{phr}$ SAF carbon black. The original authors fit the relaxation to two exponential functions. This gives four adjustable parameters, which described the data well, leading to the authors' conclusion that both a free and an immobile domain are existent. In Figure 4 we fit this same data to the Weibull function, ${ }^{47}$

$$
M(t)=A \exp \left(-t / T_{2}\right)^{\beta}
$$

where $A$ and $\beta$ are constants. When the exponent falls in the range $0<\beta \leq 1$, the Weibull function is equivalent to the KWW function. ${ }^{48,49}$ The exponential and Gaussian functions are recovered for $\beta=1$ and 2, respectively. (A historical discussion of these equations can be found in Ref. 50) As seen in Fig. 4, a good (albeit imperfect) fit to the experimental data is achieved despite one less free parameter. The results of the fitting procedure are listed in Table III, along with the original results of Kaufman. ${ }^{39}$ Note that if a small constant background term were first subtracted from the NMR data (as is often required to remove extraneous contributions, ${ }^{38}$ ) the fit using Equation (1) improves noticeably. The important point is that the NMR data can be described well without resort to the assumption of two domains. It is the assumption of exponential decay (homogenous, independent relaxation) for all phases present that necessitates the use of more than one term in the fitting function. 
TABLE III

Fit Parameters for Equation (1) to the NMR Decay Curves for Filled BR (Figure 4)

\begin{tabular}{lcccc}
\hline $\mathrm{T}\left({ }^{\circ} \mathrm{C}\right)$ & $\beta$ & $\mathrm{T}_{2}(\mu \mathrm{s})$ & $\mathrm{A}$ & Ref. \\
\hline-70 & 1 & $130 / 48$ & $0.77 / 0.23$ & {$[39]$} \\
& 0.83 & 18 & 1 & this work \\
\hline 12 & 1 & $200 / 20$ & $0.84 / 0.16$ & {$[39]$} \\
& 0.75 & 170 & 1 & this work \\
\hline
\end{tabular}

The one-pulse FID curves in Fig. 4 extend only to $100 \mu$ s; measuring the relaxation over longer times requires the use of multiple pulse sequencing. Cohen-Addad and Ebengou ${ }^{51}$ deduced the amount of immobilized rubber by extrapolating the proton relaxation curve determined from a spin echo experiment to the initial value determined from the FID. Shown in Figure 5 , this extrapolation assumes that the refocusing of the pulse is perfect and, more problematic, that the protons all belong to the polymer. The low resolution NMR method cannot distinguish among different protons, and indeed in subsequent work Cohen-Addad and Frebourg ${ }^{38}$ found that subtracting the contribution of organic impurities yielded decay curves that extrapolated to the FID initial value (Figure 5); that is, only a single polybutadiene "mobility" is observed. Thus, when correctly analyzed, the NMR experiments give no evidence of a glassy shell at the filler interface. Berriot et al. ${ }^{45}$ carried out similar NMR experiments on polyethylacrylate containing silica particles (diameter $\sim 60 \mathrm{~nm}$ ), and likewise identified the fast decay with a "glassy shell" of immobilized polymer near the silica surface. It is unclear the degree to which the alternative interpretation in Ref. 38 might affect the conclusions of Ref. 45

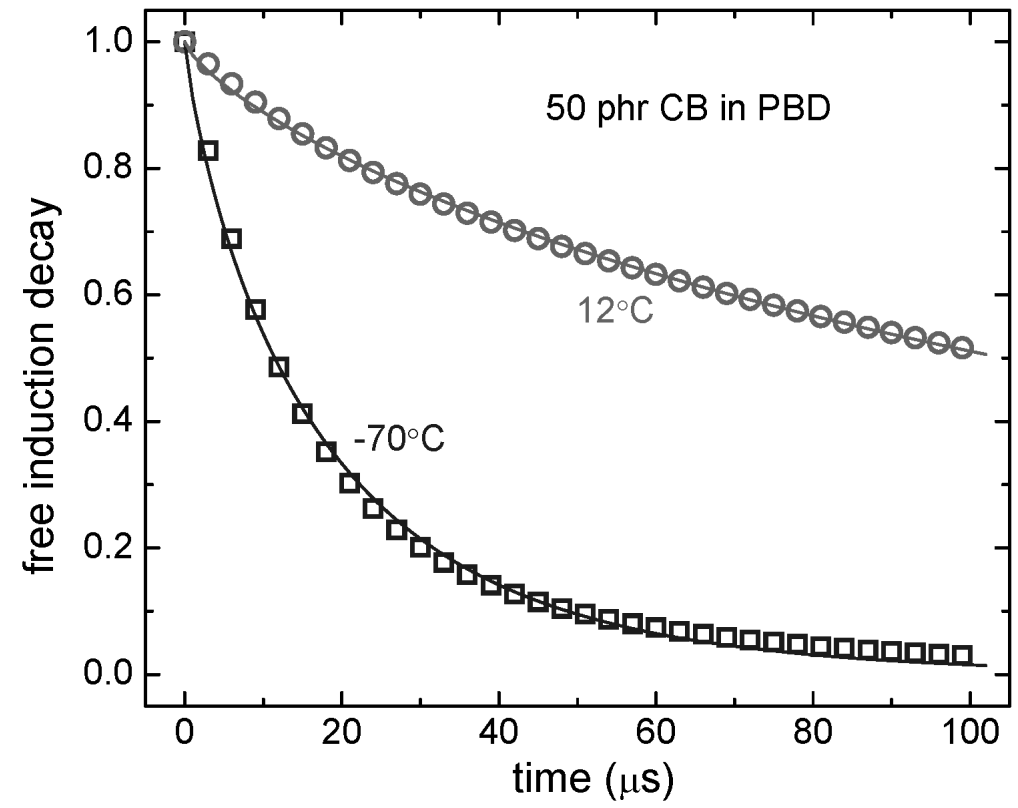

FIG. 4. - NMR FID measured at the indicated temperatures in a filled rubber. ${ }^{39}$ The solid lines are fits to the Equation (1) using just one term, whereas in the original work two terms were used (see Table III). 

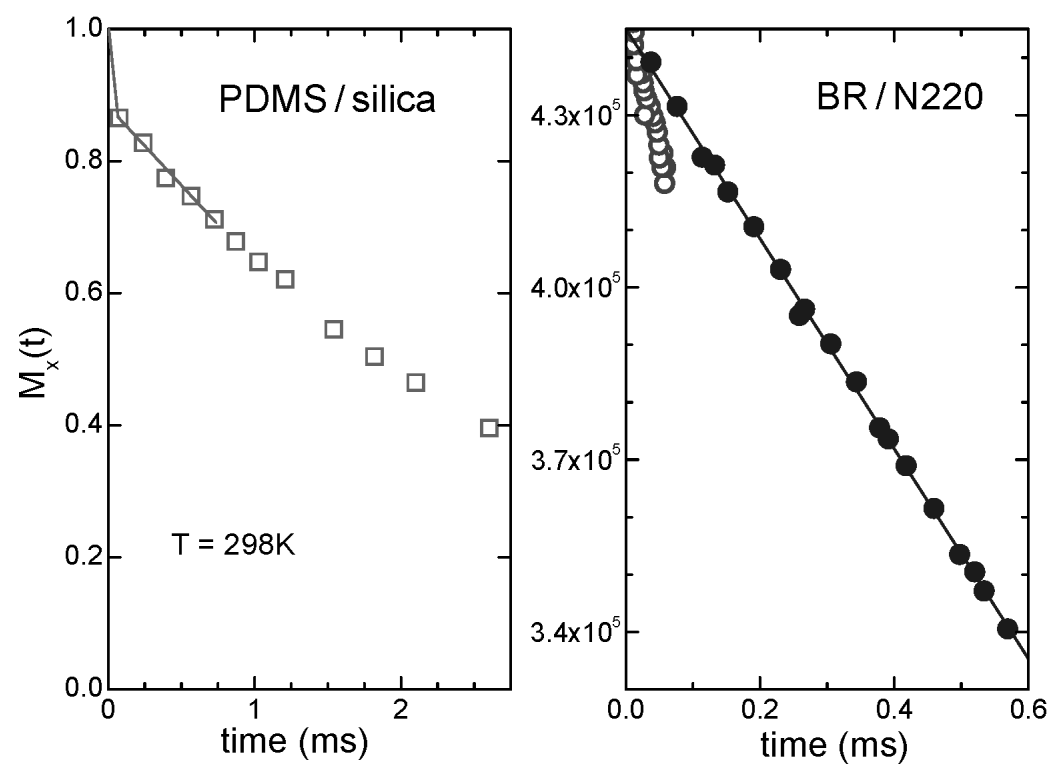

FIG. 5. - (Left) Proton spin relaxation data on a PDMS absorbed on silica particles [adapted from Ref. 51 with permission]. The extrapolation of the ordinate to the initial value of the FID measurement requires a different slope, which was interpreted as evidence of a less mobile polymer phase. (Right) Free induction decay (open circles) and spin-echoes (solid circles) from a carbon black filled BR after washing to remove organic impurities [adapted from Ref. 38 with permission]. The FID intensity extrapolates smoothly to zero time, unlike the spectra before removal of organic impurities, so that the putative evidence for immobilized polymer near the filler is gone.

There are various NMR studies that concluded there was no immobilized rubber or higher $T_{g}$ phase in the interfacial region, ${ }^{34,35,38,44,52-55}$ while others reached the opposite conclusion. ${ }^{33,36,39,41,42,45,51,56,57}$ It is clear that at least some of the NMR results suggesting the presence of immobilized rubber in the vicinity of filler are open to alternative interpretation. Nonetheless, adsorbed chain units are present in filled rubber, the result of specific interaction with moieties on the particle surface. This bonding is responsible for bound rubber. ${ }^{58}$ However, the attached segments are too few to be equated with a domain of immobilized polymer. For carbon blackfilled BR with as much as $15 \%$ bound rubber, the adsorbed segments were too sparse to be detected by NMR. ${ }^{38}$ Direct evidence of bound segments was seen in NMR measurements on PMMA adsorbed onto silica substrates. ${ }^{59}$

\section{DIELECTRIC SPECTROSCOPY}

Dielectric relaxation studies of the effect of filler on the mobility of adjacent polymer chains have been limited primarily to two groups, which reached diametrically opposite conclusions (Table IV). Fragiadakis et al. ${ }^{60-62}$ observed a new, lower frequency (higher temperature) peak in the dielectric loss of polydimethylsiloxane mixed with silica particles. They ascribed the peak to a 2-3 nm interfacial polymer layer having retarded dynamics (Figure 6). They reported similar results for an epoxy with added diamond particles. ${ }^{63}$ On the other hand, Bogoslovov et al. ${ }^{64}$ found no change in the shape of the loss peak upon addition of silica particles to polyvinylacetate (Figure 7). There are differences in these works, which might account for the contrary results. Since the polymers were not the same, the possibility exists for different interaction at the filler surface. For example, it has been found that grafting of material to deactivate the particle surface eliminates most of the immobilization. ${ }^{65,66}$ This is counter-intuitive since the immo- 
bilized domain ostensibly comprises chain segments in spatial proximity to the particle surface, without necessarily being chemically attached. A more important difference is that while the PVAc used in Ref. ${ }^{64}$ was completely amorphous, PDMS crystallizes, with the degree of crystallization influenced by the filler. ${ }^{62}$ It is well-known that in semicrystalline polymers, segments near crystallites have slower dynamics and a broadened loss peak. ${ }^{67,68}$ Another difference between the two studies is that while both groups used silica filler, Fragiadakis et al. ${ }^{60-62}$ synthesized the $\mathrm{SiO}_{2}$ particles in situ by hydrolysis and condensation of tetraethoxysilane, yielding particles having a mean diameter of $\sim 10 \mathrm{~nm}$. This is an order of magnitude smaller than the silica used by Bogoslovov et al. ${ }^{64}$ Whether the appearance of a new dielectric peak in the silicafilled PDMS represents an immobilized phase arising due to the small reinforcing particles or is an artifact of crystallization is an open question.

TABLE IV

DieleCtric SPECTROSCOPY Results

\begin{tabular}{lll}
\hline System & Conclusion & Reference \\
\hline Diamond particles in epoxy & Slower segmental dynamics & Ref. [63] \\
\hline Silica in PDMS & $\begin{array}{l}\text { Slower segmental dynamics } \\
\text { and higher } T_{g}\end{array}$ & Ref. [60,61,62] \\
\hline Silica in PVAc & No immobilzation & Ref. [64] \\
\hline
\end{tabular}

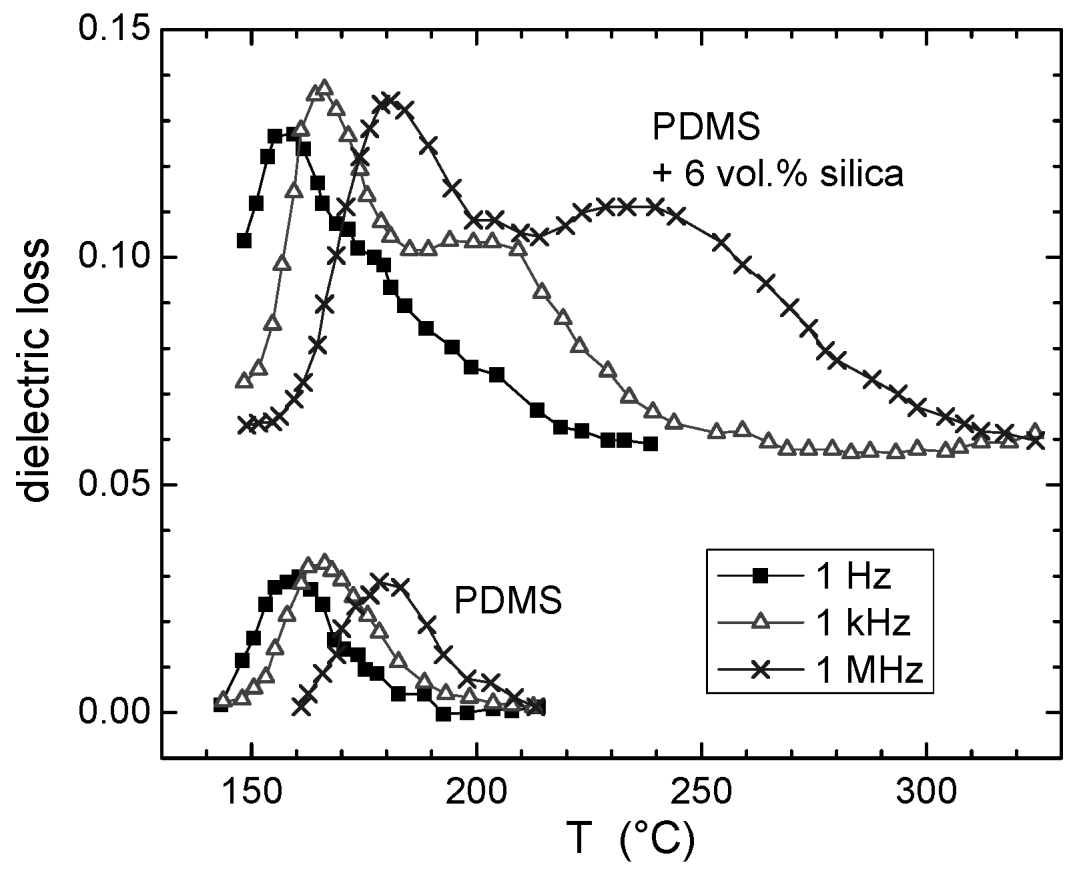

FIG. 6. - Dielectric loss versus temperature for PDMS unfilled (lower curves) and with $6 \%$ silica (upper curves) at the three indicated frequencies. There is a shoulder on the high temperature side for the filled sample. (Adapted from Ref. 62) 


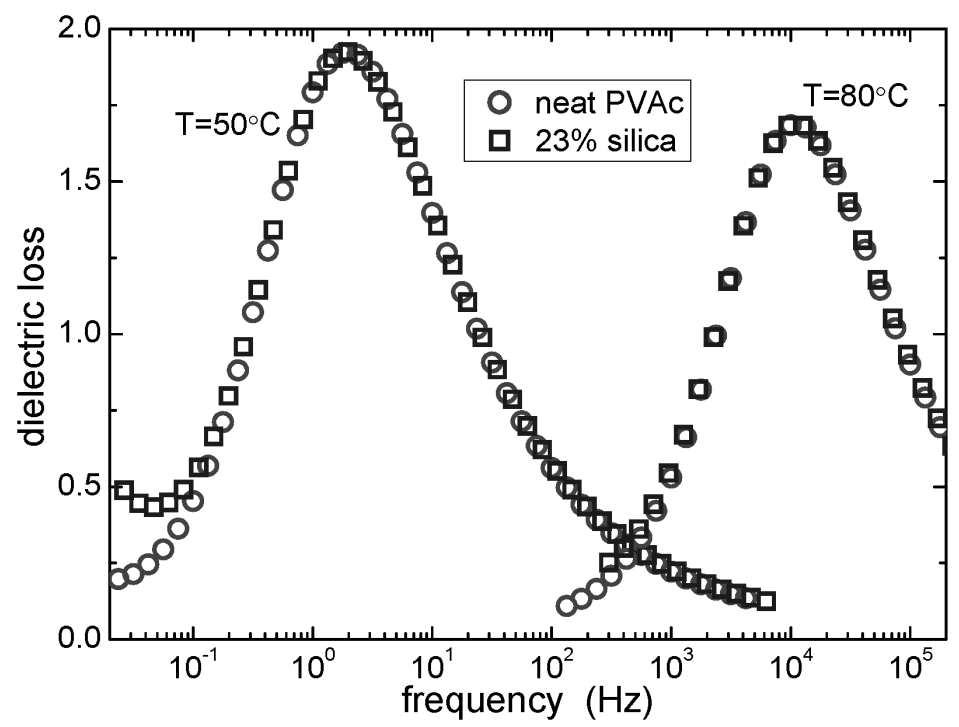

FIG. 7. - Local segmental relaxation dispersion in the dielectric loss for polyvinylacetate unfilled (circles) and with $23 \%$ silica (squares) at the indicated temperatures. Dividing the peak for the filled PVAc by 0.66 to normalize for the mass fraction of polymer superposes the spectra at each temperature. The rise towards lower frequencies is due to dc conductivity. (Adapted from Ref. 64)

\section{CALORIMETRY}

Differential scanning calorimetry (DSC) yields a direct measure of $T_{g}$ from the abrupt change in the heat capacity upon heating or cooling a sample. Only the onset of the segmental dynamics will effect a sufficient change in the heat capacity, with secondary relaxations, vibrations, torsional motions of the chain units, etc. exerting a negligible effect on the calorimetric response. Thus, DSC would seem to be an unambiguous indicator of a glassy polymer domain in the presence of filler. Results are summarized in Table V.

TABLE V

CALORIMETRY

\begin{tabular}{lll}
\hline System & Conclusion & Reference \\
\hline Carbon black in NR & no change in $T_{g}$ & Ref. [37] \\
\hline Silica in PVAc & no change in $T_{g}$ & Ref. [64] \\
\hline Silica in PDMS & no change in $T_{g}$, but broader peak & Ref. [69] \\
\hline Silica in polyurethane & no change in of $T_{g}$ & Ref. [70] \\
\hline Silver/carbon particles in PMMA & 14 deg increase in $T_{g}$ & Ref. [72] \\
\hline Alumina particles in PMMA & decrease in $T_{g}$ & Ref. [73] \\
\hline Silica w/ grafted PS in PS & PS Mw $<70 \mathrm{~kg} / \mathrm{mol}$ & Ref. [74] \\
& wets particles and $\mathrm{T}_{\mathrm{g}}$ & \\
& increases; higher $\mathrm{M}_{\mathrm{w}}$ PS doesn't & \\
& wet and $\mathrm{T}_{\mathrm{g}}$ decreases. & \\
\hline
\end{tabular}

Arrighi et al. ${ }^{69}$ found no change in the DSC $T_{g}$ of PDMS with either 7 or $20 \mathrm{~nm}$ diameter silica particles. The DSC transition was broadened in the filled rubber, but interpretation of the broadening was obfuscated by the presence of crystallinity in the polymer. A similar absence of 
any change in the DSC glass transition was reported by Bogoslovov ${ }^{64}$ for filled PVAc; both $T_{g}$ and the magnitude of the heat capacity increment (after normalization by the polymer content) were unaffected by incorporation of $100 \mathrm{~nm}$ silica particles. Rodriguez et al. ${ }^{70}$ also found that $T_{g}$ of a polyurethane was the same with or without silica particles (diameter $\leq 175 \mathrm{~nm}$ ). Very large alumina particles $(109 \mu \mathrm{m})$ had no effect on the calorimetric $T_{g}$ of polyacrylic acid, even when interaction was promoted by polymerizing the polymer in the presence of the alumina. ${ }^{71}$ On the other hand, silver/carbon nanoparticles $(9 \mathrm{~nm})$ increased the $T_{g}$ of PMMA. ${ }^{72}$

There are two studies of particle-reinforced polymer that show a decrease in $T_{g}$. Ash and coworkers ${ }^{73}$ found that $0.5 \%$ or more by weight of $39 \mathrm{~nm}$ alumina particles reduced the $T_{g}$ of PMMA by as much as $25{ }^{\circ} \mathrm{C}$. When the particles were coated with an alkylsilane to increase compatibility with the polymer, no change in $T_{g}$ was observed. Bansai ${ }^{74}$ grafted polystyrene chains $(110 \mathrm{~kg} / \mathrm{mol}$ molecular weight) onto $14 \mathrm{~nm}$ silica particles, which were then mixed with additional PS. If the latter was low molecular weight $(<880 \mathrm{~g} / \mathrm{mol})$, it wetted the particles and increases in $T_{g}$ of as much as $4{ }^{\circ} \mathrm{C}$ were observed at 5 weight $\%$ silica. However, if the polymer matrix was higher molecular weight PS, which did not wet the particles, the result was a reduction of the glass transition temperature by about the same amount.

Summarizing, DSC experiments generally show a lack of change of $T_{g}$ upon incorporation of silica or carbon black particles. For atypical fillers such as alumina particles or silica with grafted polymer, decreases of $T_{g}$ have been observed in some cases.

\section{DILATOMETRY}

Analogous to the heat capacity detection of $T_{g}$ in DSC measurements, the glass transition has a signature in the smeared step change in thermal expansion coefficient in a dilatometry experiment. Accurate volume measurements are more difficult than calorimetry and thus only a few studies ${ }^{64,75-77}$ have reported the glass transition of filled polymers by dilatometry (Table VI). The earliest was by Mason, ${ }^{75}$ who found no $T_{g}$ shift in natural rubber filled with either a larger particle MT carbon black or a tenfold-smaller HAF carbon black at filler concentrations up to $18 \%$ by volume. Since this was unexpected, Mason prepared other compositions, which exhibited the same $T_{g}$ invariance. This 1960 work illustrates the general anticipation, present even today, that small particles will modify the glass transition of the surrounding polymer. A later investigation by Kraus and Gruver ${ }^{76}$ on carbon black filled SBR found no change in $T_{g}$ from addition of MT carbon black, and only weak effects $\left(0.2{ }^{\circ} \mathrm{C}\right.$ increase in $T_{g}$ for every $10 \mathrm{phr}$ of filler) for HAF. Kraus and Gruver ${ }^{76}$ also found that the thermal expansion coefficient of the rubber was minimally influenced by the filler, consistent with the absence of a glassy polymer interphase near the carbon black surface.

TABLE VI

DILATOMETRY

\begin{tabular}{lll}
\hline System & Conclusion & Reference \\
\hline Silica in PVAc & No change in $T_{g}$ & Ref. 64 \\
\hline Carbon black in NR & No change in $T_{g}$ & Ref. 75 \\
\hline Carbon black in SBR & $\begin{array}{l}\text { Increased } T_{g} \text { for } \\
\text { adsorbed chains }\end{array}$ & Ref. 76 \\
\hline Silica in PDMS & $\begin{array}{l}\text { Increased } T_{g} \text { but effect } \\
\text { absent for methanol- } \\
\text { treated silica }\end{array}$ & Ref. 77 \\
\hline
\end{tabular}


Yim and St. Pierre ${ }^{77}$ studied silica-reinforced PDMS at concentrations up to $15 \%$ by volume and found increases in the dilatometric $T_{g}\left(\leq 8^{\circ} \mathrm{C}\right)$. However, no $T_{g}$ shift was noted for composites formed from methanol-treated silica, which led the authors to surmise that the extent of polymer mobility modification by particles was dependent on the detailed interactions between them. Similar conclusions about the importance of the details of the interfacial interaction have been reported recently. ${ }^{78,79}$ In a subsequent publication, Yim and St. Pierre ${ }^{80}$ demonstrated that the treatment of particle surfaces to alter the interfacial energetics also modified the polymer crystallization behavior in silica-reinforced PDMS. This raises the possibility that the changes in $T_{g}$ found in the earlier work ${ }^{77}$ may be a consequence of this crystallization rather than arising from a direct effect of the particles on the segmental dynamics. As mentioned above, crystalline regions have a well-known effect on $T_{g}$ of adjacent amorphous chains. ${ }^{67,68}$

Bogoslovov et al. ${ }^{64}$ recently showed that the volumetric $T_{g}$ was invariant to filler in silicareinforced PVAc. Furthermore, the magnitude of the change in thermal expansivity at $T_{g}$ reflected the contribution of all of the PVAc. Subtracting the contributions of bound or occluded polymer, the amounts of which were determined independently, severely under-predicted the measured response. In other words, polymer "bound" to the silica (in the sense that it augmented the melt viscosity and could not be removed by solvent extraction) did not exhibit any altered glass transition behavior.

\section{NEUTRON SCATTERING}

A very limited number of studies have employed neutron scattering to probe particleinduced modifications to polymer segmental dynamics (Table VII). Nakatani and coworkers ${ }^{81}$ measured the inelastic neutron scattering of polyisoprene below its glass transition temperature, both without filler and mixed with different carbon blacks (N229, graphitized N229, and N762). The samples were extracted to remove the soluble polymer prior to the measurements. They found that carbon black enhanced the librational motions of the chain backbone; i.e., rotations and torsional motions of the chain units (the segmental dynamics associated with the glass transition did not occur because the samples were below $T_{g}$ ). Thus, the authors concluded that chains bound to the carbon black particles had greater mobility than the neat polymer. ${ }^{81}$

TABLE VII

INELASTIC NEUTRON SCATTERING

\begin{tabular}{lll}
\hline System & Conclusion & Reference \\
\hline Silica in PDMS & Immobilized interfacial layer & Ref. [69] \\
\hline Silica in PDMS and PVAc & $\begin{array}{l}\text { Small fraction of chains } \\
\text { with restricted mobility }\end{array}$ & Ref. [82] \\
\hline Carbon black in IR & $\begin{array}{l}\text { Increased mobility for } \\
\text { interfacial chains }\end{array}$ & Ref. [81] \\
\hline
\end{tabular}

Arrighi et al. ${ }^{69}$ determined the incoherent dynamic structure factor from the elastic scattering intensity for PDMS, neat and mixed with silica particles (as small as $7 \mathrm{~nm}$ diameter). Deviation from a linear response of the normalized intensity (the Debye-Waller factor) in a semilogarithmic plot versus temperature reflects molecular motions other than vibrations; thus, a decrease at $T_{g}$ signals the onset of local segmental motion. Because the PDMS is semi-crystalline, this decrease at $T_{g}$ is small (data are shown in Figure 8). Although the scatter is substantial, the authors ascribed the smaller reduction in the DWF for the filled PDMS to an immobilized layer. Note that these same samples showed no change in calorimetric $T_{g}$ due to the filler. ${ }^{69}$ 


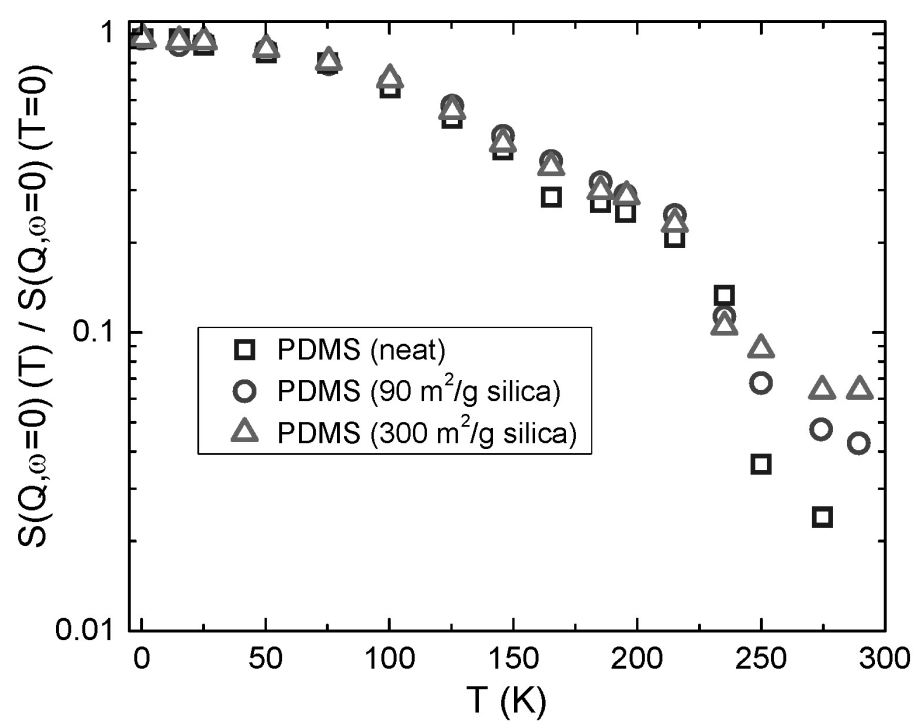

FIG. 8. - Change in elastic scattering intensity for PDMS neat and with $23 \%$ by volume silica particles (having the indicated surface area). The smaller decrease in the QENS intensity just above $\mathrm{T}_{\mathrm{g}}(=150 \mathrm{~K})$ was interpreted as evidence for immobilization of the polymer in the vicinity of the filler. The larger changes above $235 \mathrm{~K}$ are due to melting of the crystalline domains. (Adapted from Ref. 69 with permission.).

This group subsequently carried out a neutron scattering study of both PDMS and PVAc containing the silica particles. ${ }^{82}$ They fitted the quasielastic scattering to a sum of a KWW function (Equation (1) with $\beta \leq 1$ ) to represent the polymer chains and a constant term to represent the (presumed) immobilized fraction. The latter increased with silica concentration and surface area. Master curves were obtained by time-temperature superpositioning the scattering data obtained both above and below the melting point of the PDMS crystals. ${ }^{82}$ It is unclear why the measurements were insensitive to the effect of the crystalline phase on the dynamics, yet these same measurements were interpreted as revealing the presence of an immobilized interfacial polymer phase.

\section{SUMMARY}

Many investigations into the effect of small particles on polymers make the assumption $a$ priori that filler reinforcement increases $T_{g}$; accordingly, measurements are undertaken for the purpose of quantifying the presumed changes in segmental dynamics. Examples of this approach include: (i) The shift of mechanical loss tangent peaks toward higher $T$ or lower frequency is ascribed to changes in the segmental dynamics, without consideration of the effect of a higher rubbery modulus on the loss tangent shape and position. (ii) NMR decay curves are fit to a sum of functions, with each term taken to describe the respective contributions of rubber phases having different extents of immobilization. Unfortunately, these fits are not always unique and alternative analysis are possible. (iii) Changes in the dielectric relaxation or thermal properties are interpreted in terms of the effect of the filler on the segmental dynamics in polymers that are semi-crystalline. Any influence the filler has on the degree and nature of the crystallinity is neglected, even though crystallinity affects the segmental response and $T_{g}$.

The proposition that reinforcing particles generally have a negligible effect on the interfacial segmental dynamics can be supported by the available data taken in toto. While there are published studies that appear to show unambiguously that polymer chains can be immobilized by the 
presence of small particles, it remains to be seen whether these instances of a "glassy interphase" are representative, or merely special cases of unusually strong and pervasive interactions of filler particles with particular polymers. Certainly the chain segments directly bonded to the filler (e.g., chemisorbed) are immobilized and can function as junctions to increase the effective crosslink density and thus the rubbery modulus. However, a large fraction of directly bonded segments are necessary to obtain a immobilized phase (note that the local segmental dynamics underlying $T_{g}$ involves conformational transitions of only a couple of backbone bonds. ${ }^{83}$ ) Such a high degree of polymer-filler bonding would impose severe entropic constraints on the chains and is not expected to be the norm.

\section{ACKNOWLEDGEMENTS}

The work at NRL was supported by the Office of Naval Research. Saint-Gobain HighPerformance Materials is gratefully acknowledged for permission for publication. We thank J.P. Yesinowski and C. Klug for insightful discussions concerning NMR.

\section{REFERENCES}

${ }^{1}$ J. B. Donnet and E. Custodero, in "Science and Technology of Rubber," 3rd Edition, J.E. Mark, B. Erman, and F.R.Eirich, Eds., Academic Press, Burlington, MA, 2005, ch. 8.

${ }^{2}$ Carbon Black-Polymer Composites, E.K. Sichel, Ed., Marcell Dekker, New York, (1982).

${ }^{3}$ G. Heinrich, M. Kluppel, T. A. Vilgis, Current Opinion Sol. State Mat. Sci. 6, 195 (2002).

${ }^{4}$ G. R. Hamed, Rubber Chem. TeChNOL. 73, 524 (2000).

${ }^{5}$ B. Adhikari, A.K. Ghosh, and S. Maiti, J. Polym. Matl. 17, 101, (2000).

${ }^{6}$ W. H. Waddell and L. R. Evans, Rubber Chem. Technol. 69, 377 (1996).

${ }^{7}$ G. R. Hamed, Rubber Chem. Technol. 80, 533 (2007).

${ }^{8}$ L. Bokobza, Polymer 48, 4907 (2007).

${ }^{9}$ J. N. Coleman, U. Khan, W. J. Blau and Y. K. Gunko, Carbon 44, 1624 (2006).

${ }^{10}$ M. Alcoutlabi and G. B. McKenna, J. Phys. Cond. Mat. 17, R461 (2005).

${ }^{11} \mathrm{G}$. Tsagaropoulos and A. Eisenberg, Macromolecules 28, 396 (1995).

${ }^{12}$ G. Tsagaropoulos and A. Eisenberg, Macromolecules 28, 6067 (1995).

${ }^{13}$ P. P. A. Smit, Rheol. Acta 5, 277 (1966).

${ }^{14}$ G. Kraus, K. W. Rollmann, and J. T. Gruver, Macromolecules 3, 92 (1970).

${ }^{15}$ A. Iqbal, L. Frormann, A. Saleem, and M. Ishaq, Polym. Comp. 28, 186 (2007).

${ }^{16}$ M. A. Kader, K. Kim, L. S. Lee, and C. Nah, J. Matl. Sci. 41, 7341 (2006).

${ }^{17}$ A. R. Greenberg, J. Matl. Sci. Lett. 6, 78 (1987).

${ }^{18}$ J. Berriot, H. Montes, F. Lequeux, D. Long, and P. Sotta, Macromolecules 35, 9756 (2002).

${ }^{19}$ C. G. Reid and A. R. Greenberg, J. Appl. Polym. Sci. 39, 995 (1990).

${ }^{20}$ C. Gauthier, E. Reynaud, R. Vassoille, and L. Ladouce-Stelandre, Polymer 45, 2761 (2004).

${ }^{21}$ Vieweg, S.; Unger, R.; Heinrich, G.; Donth, E., J. Appl. Polym. Sci. 73, 495 (1999).

${ }^{22}$ Arrighi, V.; McEwen, I. J.; Qian, H.; Serrano Prieto, M. B., Polymer 44, 6259 (2003).

${ }^{23}$ C. G Robertson, C. J. Lin, M. Rackaitis, and C. M. Roland, Macromolecules 41, 2727 (2008).

${ }^{24}$ C. G. Robertson, C. A. Garcia-Franco, S. Srinivas, J. Polym. Sci. Polym. Phys. 42, 1671 (2004).

${ }^{25}$ M. J. Struglinski, W. W. Graessley, Macromolecules 18, 2630 (1985).

${ }^{26}$ L. J. Kasehagen, C. W. Macosko, D. Trowbridge, and F. Magnus, Rheol. 40, 689 (1996).

${ }^{27}$ K. Urayama, K. Yokoyama, and S. Kohjiya, Macromolecules 34, 4513 (2001).

${ }^{28}$ S. Ndoni, A. Vorup, and O. Kramer, Macromolecules 31, 3353 (1998).

${ }^{29}$ O. Kramer, R. Greco, R.A. Neira, and J.D. Ferry, J. Polym. Sci. Polym. Phys. 12, 2361 (1974). 
${ }^{30}$ M. A. Osman and A. Atallah, Polymer 47, 2357 (2006).

${ }^{31}$ V. M. Lobe and J. L. White, Polym. Eng. Sci. 19, 617 (1979).

${ }^{32}$ Z. Zhu, T. Thompson, S. Q. Wang, E. D. von Meerwall, and A. Halasa Macromolecules 38, 8816 (2005).

${ }^{33}$ C. R. Dybowski and R. W. Vaughan, Macromolecules 8, 50 (1975).

${ }^{34}$ J. Schaefer, S. H. Chin, and S. I. Weissman, Macromolecules 5, 798 (1972).

${ }^{35}$ N. K. Dutta, N. R. Choudhury, B. Haidar, A. Vidal, J. B. Donnet, L. Delmotte and J. M. Chezeau, Polymer 35, 4293 (1994)

${ }^{36}$ V. M. Litvinov and P. A. M. Steeman, Macromolecules 32, 8476 (1999).

${ }^{37}$ J. C. Kenny, V. J. McBrierty, Z. Rigbi, D. C. Douglass, Macromolecules 24, 436 (1991).

${ }^{38}$ J. P. Cohen Addad and P. Frebourg, Polymer 37, 4235 (1996).

${ }^{39}$ S. Kaufman, W. P. Slichter, and D. D. Davis, J. Polym. Sci. Polym. Phys. 9, 829 (1971).

${ }^{40}$ T. Nishi, J. Polym. Sci. Polym. Phys. Ed. 12, 685 (1974).

${ }^{41}$ H. Luchow, E. Breier and W. Gronski, Rubber. Chem. Technol. 70, 747 (1997).

${ }^{42}$ N. Kida, M. Ito, F. Yatsuyanygi, and H. Kaido, J. Appl. Polym. Sci. 61, 1345 (1996).

${ }^{43}$ J. P. Cohen-Addad and R. Dupeyre, Polymer 24, 400 ( 1983).

${ }^{44}$ J. Leisen, J. Breidt, and J. Kelm, Rubber Chem. TeChnol. 72, 1 (1999).

${ }^{45}$ J. Berriot, F. Lequeux, L. Monnerie, H. Montes, D. Long, and P. Sotta, J. Non-Cryst. Sol. 307-310, 719 (2002).

${ }^{46}$ G. Simon, K. Baumann, and W. Gronsky, Macromolecules 25, 3624 (1992).

${ }^{47}$ W. Weibull, J. Appl. Mech. 18, 293 (1951).

${ }^{48}$ R. Kohlrausch, Pogg. Ann. Phys. Chem. 91, 179 (1854).

${ }^{49}$ G. Williams and D.C. Watts, Trans. Farad. Soc. 66, 80 (1970).

${ }^{50}$ M. Cardona, R.V. Chamberlin and W. Marx, "Comment on the History of the Stretched Exponential Function, arXiv:0710.4446, http://arxiv.org/ftp/arxiv/papers/0710/0710.4446.pdf (October 2007).

${ }^{51}$ J. P. Cohen-Addad and R. Ebengou, Polymer 33, 379 (1992).

${ }^{52}$ W. Hu, M. D. Ellus, A. H. Tsou, S. Datta, Rubber Chem. Technol. 80, 1 (2007)

${ }^{53}$ M.A. Waldrop and G. Kraus, Rubber Chem. Technol. 42, 1155 (1969).

${ }^{54}$ W. R. Moore in "Progress in Polymer Science," Vol. I, A.D. Jenkins, Ed., Pergamon Press, Oxford, 1967, p 1.

${ }^{55}$ J. O’Brien, E. Cashell, G. E. Wardell and V. J. McBrierty, Macromolecules 9, 653 (1976).

${ }^{56}$ H. Serizawa, T. Nakamura, M. Ito, K. Tanaka, and A. Nomura, Polymer J. 15, 201 (1983).

${ }^{57}$ R. J. Roe, D. D. Davis, and T. K. Kwei, Bull. Am. Phys. Soc. II 15, 308 (1970).

${ }^{58}$ B. Meissner, J. Appl. Polym. Sci. 50, 285 (1993).

${ }^{59}$ B. Metin and F.D. Blum, J. Chem. Phys. 125, 054707 (2006).

${ }^{60}$ D. Fragiadakis, P. Pissis, and L. Bokobza, Polymer 46, 6001 (2005).

${ }^{61}$ D. Fragiadakis, P. Pissis, L. Bokobza, J. Non-Cryst. Sol. 352, 4969 (2006).

${ }^{62}$ D. Fragiadakis and P. Pissis, J. Non-Cryst. Sol. 353, 4344 (2007).

${ }^{63}$ P. Pissis and D. Fragiadakis, J. Macro. Sci. Phys. 46, 119 (2007).

${ }^{64}$ R. B. Bogoslovov, C.M. Roland, A. R. Ellis, A. M. Randall, and C. G. Robertson, Macromolecules 41, 1289 (2008).

${ }^{65}$ Y. C. Ou, Z. Z. Yu, A. Vidal, J. B. Donnet, J. Appl. Polym. Sci. 59, 1321 (1996).

${ }^{66}$ A. P. Legrand, N. Lecomte, A. Vidal, E. Papirer, J. Appl. Polym. Sci. 46, 2223 (1992).

${ }^{67}$ N. G. McCrum, B. E. Read, B. E. and G. Williams, Anelastic and Dielectric Effects in Polymer Solids; Wiley: London (1967).

${ }^{68}$ K. L. Ngai and C. M. Roland, Macromolecules 26, 2688 (1993).

${ }^{69}$ V. Arrighi, J. S. Higgins, A. H. Burgess, and G. Floudas, Polymer 39, 6369 (1998).

${ }^{70}$ J. G. I. Rodriguez, P. Carreira, A. Garcia-Diez, D. Hui, R. Artiaga and L. M. Liz-Marzan, J. Therm. Anal. Calorim. 87, 45 (2007). 
${ }^{71}$ T. Caykara and O. Guven, Polym. Composites 19,193 (1998).

${ }^{72}$ E. I. Lopez-Martinez, A. Marquez-Lucero, C. A. Hernandez-Escobar, S. G. Flores-Gallardo, R. Ibarra-Gomez, M. J. Yacaman and E. A. Zaragoza-Contreras, J. Polym. Sci. Polym. Phys. 45, 511 (2007).

${ }^{73}$ B. J. Ash, L. S. Schadler and R. W. Siegel, Mat. Lett. 55, 83 (2002).

${ }^{74}$ A. Bansai, H.Yang, C. Li, B. C. Benicewicz, S. K. Kumar and L. S. Schadler, J. Polym. Sci. Polym. Phys. 44, 2944 (2006).

${ }^{75}$ P. Mason, J. Appl. Polym. Sci. 4, 212 (1960).

${ }^{76}$ G. Kraus and J. T. Gruver, J. Polym. Sci.: Part A2: Polym. Phys. 8, 571 (1970).

${ }^{77}$ A. Yim and L. E. St. Pierre, J. Polym. Sci.: Polym. Lett. 7, 237 (1969).

${ }^{78}$ P. Rittigstein, and J. M. Torkelson, J. Polym. Sci.: Polym. Phys. 44, 2935 (2006).

${ }^{79}$ K. J. Lee, D. K. Lee, Y. W. Kim, W. S. Choe,; and J. H. Kim, J. Polym. Sci.: Polym. Phys. 45, 2232 (2007).

${ }^{80}$ A. Yim and L. E. St. Pierre, J. Polym. Sci. Polym. Lett. 8, 241 (1970).

${ }^{81}$ A. I. Nakatani, R. Ivkov, P. Papanek, H. Yang and M. Gerspacher, Rubber Chem. Technol. 73, 847 (2000).

${ }^{82}$ S. Gagliardi, V. Arrighi, R. Ferguson and M. T. F. Telling, Physica B 301, 110 (2001).

${ }^{83}$ C. K. Hall and E. Helfand, J. Chem. Phys. 77, 3275 (1982).

[ Received April 2008 ]

\section{APPENDIX}

Abbreviations

$\mathrm{BR}$ - polybutadiene

DSC - differential scanning calorimetry

DWF - Debye-Waller factor

FID - free induction decay

G' - dynamic storage shear modulus

G" - dynamic loss shear modulus

HAF - high abrasion furnace carbon black $($ ASTM designation = N330)

IR - 1,4-polyisoprene

KWW - Kohlrausch-William-Watts

MT - medium thermal carbon black (ASTM designation $=$ N990)

NMR - nuclear magnetic resonance

$\mathrm{NR}$ - natural rubber

PDMS - polydimethylsiloxane

PMMA - polymethylmethacrylate

PBD - polybutadiene

PS - polystyrene

PVAc - polyvinylacetate

SAF - super abrasion furnace carbon black $($ ASTM designation $=$ N110)

SBR - styrene-butadiene copolymer

$\mathrm{T}$ - temperature 